\title{
Connectivism: Learning theory of the future or vestige of the past?
}

\author{
Rita Kop \\ University of Wales Swansea
}

\author{
Adrian Hill \\ Open School BC, Canada
}

\begin{abstract}
Siemens and Downes initially received increasing attention in the blogosphere in 2005 when they discussed their ideas concerning distributed knowledge. An extended discourse has ensued in and around the status of 'connectivism' as a learning theory for the digital age. This has led to a number of questions in relation to existing learning theories. Do they still meet the needs of today's learners, and anticipate the needs of learners of the future? Would a new theory that encompasses new developments in digital technology be more appropriate, and would it be suitable for other aspects of learning, including in the traditional class room, in distance education and e-learning? This paper will highlight current theories of learning and critically analyse connectivism within the context of its predecessors, to establish if it has anything new to offer as a learning theory or as an approach to teaching for the 21st Century.
\end{abstract}

Keywords: e-Learning; online learning; open learning; distance education; pedagogy; learning theory; educational theory

\section{Introduction}

To what extent do existing learning theories meet the needs of today's learners, and anticipate the needs of learners of the future? Since Siemens' Connectivism: Learning as Network Creation (2005) and Downes' An Introduction to Connective Knowledge (2005) initially garnered increasing attention in the blogosphere in 2005, an extended discourse has ensued in and around the status of connectivism as a learning theory for the digital age. Kerr (2007d) identifies two purposes for the development of a new theory: it replaces older theories that have become inferior, and the new theory builds on older theories without discarding them, because new developments have occurred which the older theories no longer explain.

If older theories are to be replaced by connectivism, then what are the grounds for this measure? If connectivism is to build on older theories, how is the integration of the old and new theories to be conducted? Forster (2007) maintains that for connectivism to be a learning theory, the theory's limitations and the full range of contexts in which learning can take place must be 
Kop \& Hill

accounted for. Otherwise, connectivism's implementation by teachers may be insufficient and misguided.

With the changes that have occurred as a result of increased accessibility to information and a rapidly evolving technological landscape, educators in higher learning institutions have been forced to adapt their teaching approaches without a clear roadmap for attending to students' various needs. The wide range of approaches and learning paths that are available to redesign curricula cause friction for educators and instructional designers who are required to deliver course materials in accordance with learning outcomes prescribed and mandated by educational institutions.

\section{Overview of Connectivism}

Connectivism is a theoretical framework for understanding learning. In connectivism, the starting point for learning occurs when knowledge is actuated through the process of a learner connecting to and feeding information into a learning community. Siemens (2004) states, "A community is the clustering of similar areas of interest that allows for interaction, sharing, dialoguing, and thinking together.”

In the connectivist model, a learning community is described as a node, which is always part of a larger network. Nodes arise out of the connection points that are found on a network. A network is comprised of two or more nodes linked in order to share resources. Nodes may be of varying size and strength, depending on the concentration of information and the number of individuals who are navigating through a particular node (Downes, 2008).

According to connectivism, knowledge is distributed across an information network and can be stored in a variety of digital formats. Learning and knowledge are said to "rest in diversity of opinions" (Siemens, 2008, para. 8). Learning transpires through the use of both the cognitive and the affective domains; cognition and the emotions both contribute to the learning process in important ways.

Since information is constantly changing, its validity and accuracy may change over time, depending on the discovery of new contributions pertaining to a subject. By extension, one's understanding of a subject, one's ability to learn about the subject in question, will also change over time. Connectivism stresses that two important skills that contribute to learning are the ability to seek out current information, and the ability to filter secondary and extraneous information. Simply put, "The capacity to know is more critical than what is actually known" (Siemens, 2008, para. 6). The ability to make decisions on the basis of information that has been acquired is considered integral to the learning process.

The learning process is cyclical, in that learners will connect to a network to share and find new information, will modify their beliefs on the basis of new learning, and will then connect to a network to share these realizations and find new information once more. Learning is considered a “.. . knowledge creation process ... not only knowledge consumption.” One’s personal learning network is formed on the basis of how one's connection to learning communities are organized by a learner.

Learners may transverse networks through multiple knowledge domains. The peripheries of knowledge fields are porous, allowing for the interdisciplinary connections to be made. Siemens asserts, "The ability to see connections between fields, ideas, and concepts is a core skill" 
Kop \& Hill

(Siemens, 2008, para. 10). The connectivist metaphor is particularly timely, since the navigation of the Internet and the means by which information is dispersed on the Internet now provides a reference point for Siemens' assertions.

\section{Is Connectivism a Learning Theory?}

Gredler (2005) refers to four constituent elements that must exist to qualify a theory as wellconstructed:

Clear assumptions and beliefs about the object of the theory should be highlighted; key terms should be clearly defined; there should be a developmental process, where principles are derived from assumptions; and it should entail an explanation of "underlying psychological dynamics of events related to learning.” (cited in Siemens 2006b, p. 28)

Juxtaposed with this framework, Siemens (2006b) suggests:

Instead of modelling our knowledge structures as hierarchical or flat, confined belief spaces, the view of networks enables the existence of contrasting elements selected on the intent of a particular research or learning activities. If the silos of traditional knowledge classification schemes are more fluid, perhaps the individual elements of different theories can be adopted, as required, to solve more nuances of learning problems. When the theory does not require adoption in its fullest (i.e. interpretivism or positivism), the task of seeking knowledge becomes more salient. (p. 29)

In Theories of Developmental Psychology, Miller (1993) distinguishes between "theory" and "developmental theory," and identifies the vast deficit that can exist between the two. In general, an emerging theory should fall within the domain of scientific research, use scientific methods, and be based on previously conducted studies. It should be logically constructed and verifiable through testing.

In contrast, a developmental theory may attempt to take strides towards becoming an established formal theory over time. Developmental theories are fertile testing grounds for ideas, which, in turn, may lead to empirical research that can then validate - or disprove - formal hypotheses posited within the framework of the scientific method. They attribute meaning to facts within the context of a broad organizational framework. The framework may place particular emphasis and interest on some facts over others, which in turn can lead to further inquiry on the basis of a prioritization of information.

Miller (1993) identifies three main tasks that developmental theories should fulfill:

- $\quad$ To describe changes within one or several areas of behaviour

- To describe changes in the relationships among several areas of behaviour

- To explain the course of development that has been described in terms of the first two tasks. (Miller, 1993, pp. 5,6) 
Kop \& Hill

How does connectivism fulfil these tasks? The model frames learning in terms of learners connecting to nodes on network, suggesting that knowledge does not reside in one location, but rather that it is a confluence of information arising out of multiple individuals seeking inquiry related to a common interest and providing feedback to one another.

Downes (1996) suggests that an 'emergentist' theory of learning must treat knowledge as 'subsymbolic'. According to Downes, knowledge is treated as “. . . a recognition of a pattern in a set of neural events [if we are introspecting] or behavioural events [if we are observing]" (para. 31). Additionally, knowledge is the experience of “. . . a mental state that is at best seen as an approximation of what it is that is being said in words or experienced in nature, an approximation that is framed and, indeed, comprehensible only from which the rich set of world views, previous experiences and frames in which it is embedded" (para. 41).

The developmental implications of Downes' definitions of learning and knowledge are farreaching. If learning transpires via connections to nodes on the network, then it follows that the maximization of learning can best be achieved through identifying the properties of effective networks, which is precisely what Downes sets out to achieve in Learning Networks and Connective Knowledge.

Connectivism is mainly concerned with cognitive development, and as such does not concentrate on explaining how connections to networks may be interpreted in relation to physical maturation or the changes that occur over time via a person's exposure to, and interaction, with the social world. This is particularly the case where explaining behavioural performance and moral development in specific contexts is concerned.

Siemens (2006b) highlights other factors that may inform the development of a new learning theory, namely "how we teach, how we design curriculum, the spaces and structures of learning, and the manner in which we foster and direct critical and creative thought in our redesign of education” (p. 6). A multitude of elements could change with the introduction of a new theory.

With the advent of new considerations in instructional design and implementation, universities are taking the task of adapting their instructional approaches seriously. The utilization of information technology in the classroom has become a feature of instruction. What remains to be established is whether connectivism holds its own as a new theoretical model to support this endeavour.

Miller (1983) maintains:

When a person develops or adopts a particular theory, she takes on a whole set of beliefs concerning what questions about development are worth asking, what methods for studying these questions are legitimate, and what the nature of development is. . . There are unwritten rules of the game that are very much part of the theory as it is practiced. (p. 5)

Perhaps with Downes' 'theory of distributed knowledge' the rules of the game have not yet fully extended from the philosophical domain into that of applied educational research, though Siemens' connectivist model is a ripe training ground for further studies. 
Kop \& Hill

\section{Epistemological Frameworks for Learning}

Siemens (2008b, p. 9) draws on the work of Driscoll in categorizing learning "into three broad epistemological frameworks” namely objectivism, pragmatism, and interpretivism. According to objectivism, reality is external to the mind, and knowledge and perception are experientially acquired. Pragmatism suggests that knowledge is a negotiation between reflection and experience, inquiry and action, and interpretivism posits that knowledge is an internal construction and is informed through socialization and cultural cues.

A fourth framework is also introduced, namely Downes' (2006) theory of distributed knowledge, which is supported by Siemens (2008b) who sees ". . . the view of knowledge as composed of connections and networked entities ...The concept of emergent, connected, and adaptive knowledge provides the epistemological framework for connectivism as a learning theory" (p. 10). Siemens sees the alignment between epistemologies and learning theories as detailed in Figure 1.

Figure 1. Alignment of Epistemologies and Learning Theories

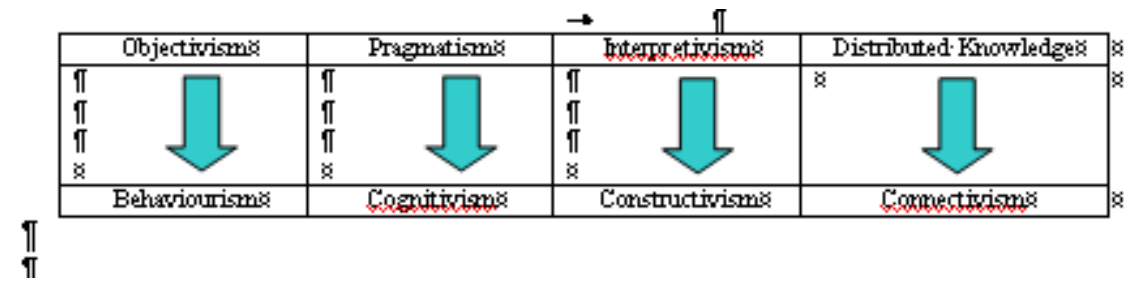

The first three are universally accepted, but the concept of connectivism as a learning theory has had some criticism, including from Verhagen (2006), who argued that the theory remains unsubstantiated philosophising. Kerr suggested that existing theories "satisfactorily address the needs of learning in today's technologically, connected age” (Siemens, 2008b). Proponents of connectivism are "exploring a model of learning that reflects the network-like structure evident in online interactions,” (p. 12) but is this enough to constitute its formulation as a new learning theory, and does connectivism have anything new to offer? Criteria must be met to establish connectivism as a learning theory. Before exploring these considerations in greater depth however, let us revisit pre-connectivist theories of learning that have influenced its development as a model.

\section{Pre-Connectivist Theories of Learning}

Kerr (2007a) contends that the relationship between internal and external knowledge environments was accounted for in Vygotsky's formulation of social constructivism, long before any explanation was provided by connectivism. Similarly, Kerr asserts that Papert's constructivism and Clark's embodied active cognition also provided explanations prior to connectivism. Communities of practice are another model that treats learning as an inherently social and situated engagement.

Vygotsky, whose name is inherently linked to social constructivism, saw two important elements in the learning process: 'language' and 'scaffolding.' Vygotsky noted how self-talk in children serves as a means by which learners may work through complex problems by externalizing them as a form of self-guidance and self-direction. From a cognitive development standpoint, this 
Kop \& Hill

observation is important because the child's social interaction with others helps formulate private speech in the child. Instructional scaffolding provides support for learning and problem solving through the use of hints, reviewing material, encouragement, and reducing complex problems into "manageable chunks" (Woolfolk, 1995, p. 49). The relationship between the individual and external knowledge is present in the relationship between what is known by the learner in question, and that knowledge to which the learner is being exposed.

Papert (1991) formulated the theory of constructionism. Constructionism contends that learning occurs through learners' engaging in creative experimentation and activity. Papert distinguishes between learning and teaching, with teaching treated as secondary to the hands-on creative process - for instance, a group of children playing with Lego blocks or creating clay sculptures are 'objects to think with.' Learning, therefore, is considered an interaction between the individual and his or her environment, a relational understanding. By extension, Papert asserts that the computer's role in learning ought to be enabling, as a means for children to use knowledge.

Clark (1997) extended Papert's position with the theory of embodied active cognition, in which he argued that the scaffolding provided by language and 'objects to think with' is a mutual interaction between mind, brain, and the environment, and may draw upon multiple theoretical frameworks (e.g., connectionist, cognitivist) to explain cognition. Kerr (2007a) suggests that the ideas that are the basis of connectivism have already been developed by Clark, and that recent widespread recognition for the work of connectivism is due to the high visibility of networks in the current age (e.g., the Internet) compared with in the past. Whereas language is so ubiquitous that it is not always noticed, network-based learning theories can now unequivocally point to existing networks, such as the World Wide Web.

Lave and Wenger (2002) researched the way people learn in their daily lives and suggested the typology of a 'community of practice,' which is based on the premises that humans are social beings, and that knowledge is developed through active engagement in valued undertakings throughout their lives. Clearly, learning does not only take place within a learning institution. According to Wenger (1998),

Our institutions ... are largely based on the assumption that learning is an individual process, that it has a beginning and an end, that it is best separated from the rest of our activities, and that it is the result of teaching. (p. 3)

Lave and Wenger (2002) do not see learning as individual; in their view learners make sense of their surroundings in a social setting, by communicating with others. Knowledge is situated within a community in which a more 'knowledgeable other' facilitates the move from the periphery to the centre of the community. People build on earlier experiences and knowledge.

\section{Downes and Siemens: Connectivism}

With connectivism, the formation of connections between nodes of information (i.e., networks) constitutes knowledge - and in addition, connectivism posits that "the ability to construct and traverse those networks" (Downes, 2007) comprises learning. As Siemens (2006b) has suggested, "the learning is the network." Downes (2007b) further states:

"Where connectivism differs from those theories, I would argue, is that connectivism denies that knowledge is propositional. That is to say, these other 
Kop \& Hill

theories are 'cognitivist', in the sense that they depict knowledge and learning as being grounded in language and logic. Connectivism is, by contrast, 'connectionist'. Knowledge is, on this theory, literally the set of connections formed by actions and experience. It may consist in part of linguistic structures, but it is not essentially based in linguistic structures, and the properties and constraints of linguistic structures are not the properties and constraints of connectivism. . . In connectivism, there is no real concept of transferring knowledge, making knowledge, or building knowledge. Rather, the activities we undertake when we conduct practices in order to learn are more like growing or developing ourselves and our society in certain (connected) ways.”

Downes (2007b) identifies "the core proposition shared between connectivism and constructivism” as knowledge 'not being acquired, as though it were a thing.' Moreover, Kerr stresses the importance of connectivism's not losing "the lessons of constructivism and the need for each learner to construct his or her own mental models in an individualistic way" (Forster, 2007, para. 1).

Verhagen (2006) criticises connectivism as a new theory, primarily because he can distil no new principles from connectivism that are not already present in other existing learning theories. Moreover, he is not convinced that learning can reside in non-human appliances.

Siemens (2006b) responded that a new learning theory, in fact, is required, due to the exponential growth and complexity of information available on the Internet, new possibilities for people to communicate on global networks, and for the ability to aggregate different information streams. Siemens argues that "knowledge does not only reside in the mind of an individual, knowledge resides in a distributed manner across a network . . . learning is the act of recognizing patterns shaped by complex networks.' These networks are internal, as neural networks, and external, as networks in which we adapt to the world around us (Siemens 2006b, p. 10).

In Miller's (1993) extended analysis of theoretical frameworks in developmental psychology, she describes contextual theories as arising out of "the intertwining of an object or person and its surroundings, the interconnectedness of contexts, and the intermingling of biology and culture" (p. 410). Presently, connectivism is lacking an extensive body of empirical research literature to lend it support. Miller (1993) argues that the "greater the distance between theory and behaviour" the greater the problems to prove or disprove the theory (p. 410).

Where connectivism draws its strength is through using Web-based activity as an example of learning looking through the connectivist lens. The analogy is intuitive and powerful because of the ubiquitous use of the Internet in today's world. In addition, Downes (2006) has elucidated an epistemological framework for distributed knowledge which provides a strong philosophical basis for the connectivist learning framework.

\section{Higher Order Thinking: Learning and knowledge transfer}

Kerr (2007b) suggests that no theory, including the connectivist model, sufficiently explains higher order thinking "as a mechanism spanning brain, perception and environment." He states that "knowledge is not learning or education." He challenges connectivism to explain "transferring understanding, making understanding and building understanding", and the internal processes that lead to "deep thinking and creating understanding." 
Kop \& Hill

Siemens suggests that when a learner is engaged in creating and recreating their own learning network, understanding arises through applying meta-cognition to the evaluation of "which elements in the network serve useful purposes and which elements need to be eliminated." Downes (2007a) contends "that 'understanding' is a distribution of connections across a network. To 'know that P' is therefore equated with 'a certain set of neural connections' that entail being in a certain physical state" unique to the experiencer of that state. The physical state in question is not distinct from the other physical states with which it is intertwined within that individual. Downes asserts that in connectivism, 'deep thinking' or 'creating understanding' are equivalent to the process of making connections, and that there are no mental models per se (i.e., no systematically constructed rule-based representational systems), and what there is (i.e., connectionist networks) is not built, like a model; but instead it is grown, like a plant.

Kerr (2007c) suggests that words and language are necessary to sustain long predictive chains of thought - e.g., to sustain a chain or combination of pattern recognition. He contends that this is true in chess, for example, where the player uses chess notation to assist his or her memory. Downes (2007a), however, raises two questions of importance in response to Kerr's assertion:

'First, do we play chess (solely) by constructing strings of inferences (i.e., sequences of moves in chess notation)? And second, even when we construct strings of inferences, is this how we actually think, or is this how we describe how we think?' (Downes, 2007a)

Though the expression of thoughts is limited by grammatical principles in language, it may be that thoughts themselves are not necessarily bound by language, and therefore at least in some cases, may not be constrained by grammatical principles.

\section{Pattern Recognition}

Downes (2006) contends that the assumption that we think in a language is misguided. He suggests that thinking is actually the arrangement of 'pieces' which are then matched to desirable (or undesirable) outcomes. What are these pieces? What gives them shape?

Whether these questions can be definitely answered, the reason for Downes' drawing the distinction between pattern matching compared with "long predictive chains of thought" is worthy of consideration. If it is the case that reasoning is a function of pattern matching, as opposed to the rule-governed principles of physical symbol systems that define linguistic structures, then the characterization of connectivism is dramatically different from that of constructivism.

Kerr's (2007a) assertion is that "the mind is a construct which is distributed from the brain to the environment." He stresses that how we answer the questions 'What is the mind?' 'Where is the mind?' and 'How does it work?' are at the heart of the development of learning theories, and that the answers have profound practical implications.

Humans may be predisposed to identifying certain patterns on the basis of their neurological makeup; these patterns, in fact, may be intrinsic qualities of mind. Kerr (2007a) refers to Kay's non-universals, a series of understandings (identified on the basis of research by anthropologists) that are not learned spontaneously, and which are common to all known human societies - for instance, "deductive abstract mathematics, model-based science, democracy [and] slow deep thinking." Kerr suggests that if learning these non-universals is considered important, then 
Kop \& Hill

methods ought to be identified to teach them. The suggestion is not to propound the existence of 'fundamental knowledge,' but to question and challenge the connectivist slogan, 'the half-life of knowledge is declining' by pointing out the importance of identifying strategies to ensure that at least some forms of learning persist.

Bruner (1999) describes a situated view of mind, where it is both represented by and understood in terms of human cultural contexts. This mode is shared by a community, and is also passed on from generation to generation to maintain the culture's way of life and identity. "Although meanings are in the mind, they find their origin and significance in the community in which they were created. . . It is culture that provides the tools for organizing and understanding our worlds in communicable ways” (Bruner 1999, p. 149).

\section{The Compatibility of Connectivism and Formal Education}

Three predominant pressures are influencing and instigating change in the dissemination and retrieval of information, each of which is fundamentally altering the formal educational landscape: millennial learners' needs are not sufficiently being met by traditional training models of instruction, information growth has necessitated new means by which to navigate and filter the information that is available, and advancing technologies are increasingly enabling learners to connect to one another and to knowledge networks of their own making (Siemens, 2008b, p. 7).

Verhagen (2006) sees that connectivism fits exactly at this level of pedagogy and curriculum rather than at the level of theory, since, in effect, people still learn in the same way, though they continue to adapt to the changing technological landscape. Learners might move away from classroom groups and a tutor to online networks and important nodes on these networks, but in effect the same activity takes place on a different scale - although learners might miss out on a layer of critical engagement as their choice of mentor could confirm rather than challenge views and opinions.

\section{Teaching in a Connected Environment}

Developers of e-learning (Siemens, 2008) propose that the increasing influence of the Internet and online connectedness of people will have implications for educational practice. The rapid development of technology and exponential growth in the use of the Internet, along with Web 2.0 and mobile developments, make new and different educational structures, organisations, and settings a possibility. The online and face-to face networks that people build-up throughout their lives will provide expertise and knowledge, in addition to the guidance that local or online tutors can provide. Learners will be at the centre of the learning experience, rather than the tutor and the institution. Learners will be instrumental in determining the content of the learning, in addition to deciding the nature and levels of communication, and who can participate.

The role of the tutor will not only change, but may disappear altogether. People can move from a learning environment controlled by the tutor and the institution, to an environment where they direct their own learning, find their own information, and create knowledge by engaging in networks away from the formal setting. They still communicate with others, but their personal interests and preferences - rather than institutional requirements and choices - are the main drivers for their engagement with more knowledgeable others in their learning. 
Kop \& Hill

The networks in which people communicate can be small or vast, but the main characteristics for networks to support knowledge development will be that they are diverse, open, autonomous, and connected (Downes, 2007c). There are parallels with Illich's (1971) educational vision of the 1970s, particularly his idea of 'community webs.' Online networks also come together as interest groups of autonomous participants, but Illich envisaged his webs in community settings and aimed at bringing local people together with learners and 'people with knowledge.' Online networks might be open and may facilitate connections, but local culture and values cannot be incorporated all that easily as the online networks are global, with diverse participants, each bringing his or her own ideas and background to the fore. This might stimulate debate, but the local community and its development would be of less importance than the dominant culture on the network.

There have been concerns about the lack of critical engagement online (Norris 2001), because of the temptation to connect with like-minded people, rather than in more challenging transactions, with experts such as the teacher in a classroom, whose role is to make people aware of alternative points of view. Critical educators, such as Freire and Macedo (1999), thought it essential that teachers have a directive role. In this capacity, teachers would enter into a dialogue "as a process of 'learning and knowing' with learners, rather than the dialogue being a 'conversation' that would remain at the level of 'the individual's lived experience.' I engage in dialogue because I recognise the social and not merely the individualistic character of knowing" (Freire \& Macedo,1999, p. 48). He felt that this capacity for critical engagement would not be present if educators are reduced to facilitators, which is the role of the tutor that has been widely accepted in e-learning (Salmon, 2004). Moreover, in a connectivist online environment, with an emphasis on informal learning and the individual's choice to engage with experts outside the classroom, this critical and localized influence could be lost completely. The lack of critical engagement by a tutor - on top of the diminishing level of control by the institution - implicates a high level of learner autonomy.

Current research in adult education shows that the levels of confidence and learner autonomy, in addition to discipline, are of crucial importance to the level of engagement by the learner in a personalized learning environment, as lack of these in the majority of participants hampered their learning online. Nearly all students preferred the help and support of the local or online tutor to guide them through resources and activities, to validate information, and to critically engage them in the course content (Kop, 2008), which would indicate the need for a localized tutor presence.

Downes and Siemens do not suggest that connectivism is limited to the online environment. The online environment is one application that has been important for the development of connectivism, but the theory applies to a larger learning environment, and helps to inform how we understand our relatedness to the world, and consequently how we learn and understand from it. Networks are not just comprised of digitally enabled communications media, nor are they exclusively based in neurological brain-based mechanisms. The networks to which Downes and Siemens are referring are the relationship between 'internal' and 'external' physical environments. As Siemens suggests, the learning is the network.

Though an increase in the ability to converse and collaborate has occurred with the advent of new information and communication technologies, Kerr (2007a) reminds us that "good educators have always recognized the importance of these things." What has changed is the scalability of communication, though it does not follow that at the level of learning theory, a new innovation or idea has been discovered: "The scaling is not actually innovation." 
Kop \& Hill

\section{Conclusion: Radical discontinuity}

Kerr (2007a) asserts that "we are entering some sort of period of radical discontinuity," and further raises the question: "What is the nature of that radical discontinuity?" In the educational domain, a multitude of Web applications are being used to enhance the learner experience, particularly in terms of collaboration and communication. New learning environments are informing present and future trends from which both educators and students stand to benefit. Moreover, the way in which global networks and communities of interest are currently being formed through emerging technologies is encouraging young people, in particular, to develop new, creative, and different forms of communication and knowledge creation outside formal education. Of course the number of learners who have been immersed in these technologies all their lives will grow, as the young are more predisposed to use the latest technologies (National Statistics, 2007) and will displace the learners who have grown up with books and pen and paper as resources for learning. This will undoubtedly cause friction in institutions and class rooms, particularly as (adult) educators themselves do not always feel comfortable with the new developments because they have not been shown adequately, or explored for themselves, how the new and emerging technologies could enhance their working practice. Furthermore, school systems have not developed a connectivist model within which to deliver curricula, partly because educational staff and institutions have not caught on to the possibilities that digital technology have to offer, and partly because not all people are autonomous learners. Additionally, school systems tend to value education that is grounded in traditions of the past, steeped in values that have developed over centuries. If, however, learners' worlds inside and outside education become too disparate, new learners who are familiar with the opportunities for learning on the Internet will be able to find their experts elsewhere. There is a need for (adult) educators to closely follow and influence the developments and the debates, and seriously research how their institutions can evolve using the emerging technologies to their and their learners' advantage. In doing so, they would ensure that (adult) education can secure its role of critical engager, and at the same time make the best use of technology - that is in making connections with information and knowledgeable others all over the world to enrich learners lives and the communities in which they live.

A paradigm shift, indeed, may be occurring in educational theory, and a new epistemology may be emerging, but it does not seem that connectivism's contributions to the new paradigm warrant it being treated as a separate learning theory in and of its own right. Connectivism, however, continues to play an important role in the development and emergence of new pedagogies, where control is shifting from the tutor to an increasingly more autonomous learner.

\section{References}

Bruner, J. (1999). Culture, mind and education. In. B. Moon \& P. Murphy (Eds.) Curriculum in Context. London: Paul Chapman Publishing and The Open University.

Clark, A. (1997). Being there: Putting brain, body and world together again. Cambridge, MA: MIT Press.

Downes, S (2007a, February 6). Msg. 30, Re: What Connectivism Is. Connectivism Conference: University of Manitoba. http://ltc.umanitoba.ca/moodle/mod/forum/discuss.php?d=12 
Kop \& Hill

Downes, S (2007b, February 3). Msg 1, Re: What Connectivism Is. Online Connectivism Conference: University of Manitoba. http://ltc.umanitoba.ca/moodle/mod/forum/discuss.php?d=12

Downes, S (2007c, February 6). Msg. 2, Re: What Connectivism Is. Online Connectivism Conference: University of Manitoba http://tc.umanitoba.ca/moodle/mod/forum/discuss.php?d=12

Downes, S. (2006, October 16). Learning networks and connective knowledge. Instructional Technology Forum: Paper 92. http://it.coe.uga.edu/itforum/paper92/paper92.html

Downes, S. (2005, December 22). An introduction to connective knowledge. Stephen's Web. http://www.downes.ca/cgi-bin/page.cgi?post=33034

Freire, P., \& Macedo, D. P. (1999). Pedagogy, culture, language, and race: A dialogue. In J. Leach \& B. Moon (Eds.) Learners and pedagogy. London: Paul Chapman.

Forster, T. (2007). Msg. 14, Re: What Connectivism Is. Online Connectivism Conference: University of Manitoba. http://ltc.umanitoba.ca/moodle/mod/forum/discuss.php?d=12

Kerr, B. (2007a). A Challenge to Connectivism. Transcript of Keynote Speech, Online Connectivism Conference. University of Manitboa. http://tc.umanitoba.ca/wiki/index.php?title=Kerr_Presentation

Kerr, B. (2007b). Msg. 1, The invisibility problem. Online Connectivism Conference: University of Manitoba. http://ltc.umanitoba.ca/ moodle/mod/forum/discuss.php?d=12

Kerr, B. (2007c, February 5). Msg. 18, Re: What Connectivism Is. Online Connectivism Conference: University of Manitoba. http://tc.umanitoba.ca/moodle/mod/forum/discuss.php?d=12

Kerr, B. (2007d, February 3). Msg. 7, Re: What Connectivism Is. Online Connectivism Conference: University of Manitoba. http://tc.umanitoba.ca/moodle/mod/forum/discuss.php?d=12

Kop, R. (2007). Blogs and wikis as disruptive technologies: is it time for a new pedagogy? In M. Osborne, M. Houston \& N. Toman. (Eds.) The Pedagogy of Lifelong Learning, Understanding effective teaching and learning in diverse contexts (pp. 192-202). London: Routledge.

Kop, R. (2008). Web 2.0 technologies: Disruptive or liberating for adult education? In Gateway to the Future of Learning, Proceedings 49th Adult Education Research Conference, June 15-17. St. Louis, MO.

Miller, P. (1983). Theories of developmental psychology. First Edition. New York: W. H. Freeman.

Miller, P. (1993). Theories of developmental psychology. Third Edition. New York. W. H. Freeman. 
Kop \& Hill

Lave J., \& Wenger. E. (2002). Legitimate peripheral participation' in Communities of Practice. In R. Harrison (Ed.) Supporting lifelong learning: Volume 1 - Perspectives on learning (pp. 111-126). London \& New York: RoutledgeFalmer.

Norris, P. (2001). Digital divide: Civic engagement, information poverty, and the internet worldwide. Cambridge: Cambridge University Press.

Oblinger, D., \& Oblinger, J. (2005). Is it age or IT: First steps towards understanding the Net Generation. In D. Oblinger \& J. Oblinger (Eds.) Educating the Net Generation. Washington, DC: Educause. www.educause.edu/educatingthenetgen/

Papert, S., \& Idit, H. (1991). Constructionism. Norwood, NJ: Ablex Publishing.

Salmon, G. (2004) e-Moderating: The key to teaching and learning online. London, Routledge Falmer

Siemens, G. (2008a). About: Description of connectivism. Connectivism: A learning theory for today’s learner, website. http://www.connectivism.ca/about.html

Siemens, G. (2008b). Learning and knowing in networks: Changing roles for educators and designers. Paper 105: University of Georgia IT Forum.

http://it.coe.uga.edu/itforum/Paper105/Siemens.pdf

Siemens, G. (2007a). Situating Connectivism. Online Connectivism Conference: University of Manitoba. Wiki entry. http://tc.umanitoba.ca/wiki/index.php?title=Situating_Connectivism

Siemens. G. (2006a). Knowing knowledge. KnowingKnowledge.com Electronic book. www.knowingknowledge.com

Siemens, G. (2006b, November 12). Connectivism: Learning theory or pastime of the selfamused? Elearnspace blog. http://www.elearnspace.org/Articles/connectivism selfamused.htm

Siemens, G. (2005, August 10). Connectivism: Learning as Network Creation. e-Learning Space.org website. http://www.elearnspace.org/Articles/networks.htm

Verhagen, P. (2006). Connectivism: A new learning theory? Surf e-learning themasite, http://elearning.surf.nl/e-learning/english/3793

Wenger, E. (1998). Communities of practice: Learning, meaning and identity. New York: Cambridge University Press.

Woolfolk, A. (1995). Educational psychology, Sixth Edition (pp. 47-51). Needham Heights, MA: Allyn \& Bacon.

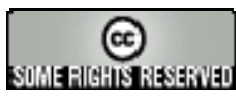

